\title{
Forest Management of Pinus pinaster Ait. in Unbalanced Forest Structures Arising from Disturbances-A Framework Proposal of Decision Support Systems (DSS)
}

\author{
Paulo Costa ${ }^{1, *}$, Adelaide Cerveira ${ }^{2}$, Jan Kašpar ${ }^{3}$, Robert Marušák ${ }^{3}\left(\mathbb{D}\right.$ and Teresa Fidalgo Fonseca ${ }^{4,5}$ (D) \\ 1 Attractive Cascade Unipessoal, Lda (CERNA Portugal), Perafita, 4450-142 Matosinhos, Portugal \\ 2 Department of Mathematics, University of Trás-os-Montes e Alto Douro, INESC-TEC Technology and \\ Science (Formerly INESC Porto, UTAD Pole), 5001-801 Vila Real, Portugal; cerveira@utad.pt \\ 3 Faculty of Forestry and Wood Sciences, Czech University of Life Sciences Prague, Kamýcká 129, \\ Praha 6 Suchdol, 16521 Prague, Czech Republic; kasparj@fld.czu.cz (J.K.); marusak@fld.czu.cz (R.M.) \\ 4 Department of Forestry Sciences and Landscape Architecture (CIFAP), University of Trás-os-Montes and Alto \\ Douro, 5001-801 Vila Real, Portugal; tfonseca@utad.pt \\ 5 Forest Research Centre (CEF), School of Agriculture, University of Lisbon, Tapada da Ajuda, \\ 1349-017 Lisboa, Portugal \\ * Correspondence: paulodanielcosta@hotmail.com
}

\section{check for} updates

Citation: Costa, P.; Cerveira, A.; Kašpar, J.; Marušák, R.; Fonseca, T.F. Forest Management of Pinus pinaster Ait. in Unbalanced Forest Structures Arising from Disturbances-A Framework Proposal of Decision Support Systems (DSS). Forests 2021, 12, 1031. https://doi.org/10.3390/ f12081031

Academic Editors: Joana Amaral Paulo and Olga Viedma

Received: 25 April 2021

Accepted: 29 July 2021

Published: 3 August 2021

Publisher's Note: MDPI stays neutral with regard to jurisdictional claims in published maps and institutional affiliations.

Copyright: (C) 2021 by the authors Licensee MDPI, Basel, Switzerland. This article is an open access article distributed under the terms and conditions of the Creative Commons Attribution (CC BY) license (https:// creativecommons.org/licenses/by/ $4.0 /)$.

\begin{abstract}
Forests assume a great socioeconomic and environmental importance, requiring good management decisions to value and care for these natural resources. In Portugal, forest land use accounts for $34.5 \%$ of the continental area. The softwood species with the highest representation is maritime pine (Pinus pinaster Ait.). Traditionally, the species is managed as pure and even-aged stands for timber production, with a rotation age of 45 to 50 years. Depending on the initial stand density, the stands are thinned 2 to 4 times during the rotation period. Disturbances associated with forest fires have a negative impact on the age structure of stands over time, as they result in a narrow range of stand ages. This age homogenization over large forest areas increases with the recurrence and size of forest fires, bringing new challenges to forest management, namely the difficulty in ensuring the long-term sustainability of the wood supply. The problem aggravates with the increasing demand pressure on pine wood. This article aims to suggest a framework of DSS for Pinus pinaster that can effectively support the management of forest areas under these circumstances, i.e., narrow age ranges and high demand of harvested timber volume. A communal woodland area in the Northern region of Portugal affected by forest fires was selected as a study case. The Modispinaster model was used as the basis of the DSS, to simulate growth scenarios and interventions along the optional rotation period. Two clear-cut ages were considered: 25 and 40 years. The results obtained were the input data for an integer linear programming (ILP) model to obtain the plan that maximizes the volume of timber harvested in the study area, during the planning horizon. The ILP model has constraints bounding the area of clearings, and sustainability, operational and forestry restrictions. The computational results are a powerful tool for guidance in the decision-making of scheduling and forecasting the execution of interventions determining the set of stands that are exploited according to the different scenarios and the period in which the clear-cut is made throughout the planning horizon. Considering all constraints, the solution allows a balanced extraction of a total of $685 \mathrm{~m}^{3} \cdot \mathrm{ha}^{-1}$, over the 50-year horizon, as well as the representation of all age classes at the end of the planning period.
\end{abstract}

Keywords: forest management; maritime pine; integer linear programming

\section{Introduction}

Forests play important roles and functions, including watershed protection, prevention of soil erosion and mitigation of climate change. Forests provide habitats for animals and livelihoods for humans and, after oceans, they are the world's largest storehouses of carbon. Inside the four major categories of ecosystem services of provisioning, regulating, cultural 
and supporting services, one major benefit of the forest, which is the main focus of this study, is wood production and the supply of timber. This activity is directly linked to the production chain (saw milling, carpentry for construction, wood packaging, furniture and other wood products) and can be of particular economic relevance in many countries. While the broad role of the functions offered by forests justifies adequate forest management and planning, the growing demand for wood on a global and national scale makes this an essential requirement, as it allows for verification of the possibility of obtaining a wood supply over a time horizon while ensuring the sustainability of the wood supply. This planning procedure goes beyond traditional "forest regulation," leading to the need for intelligent management of unbalanced forest structures [1] and of specific and advanced tools.

The application of computerized tools designated as decision support systems (DSS) emerged at the beginning of the 1980s. DSS are computerized technological resources capable of supporting business and organizational decision-making activities by compiling useful information through data analysis, model study, and support tools designed to assist decision makers in identifying and solving problems [2-8]. They aim to provide the best decision-making process by improving the efficiency and productivity of managers and professionals [9]. The application of DSS to decision-making in forestry has been increasing over the years, embracing different problems and goals (e.g., [10,11] and references herein).

DSS presents particular interest when optimized management solutions for forestlevel planning are the aim. Forest DSS can help forest managers in management planning by building knowledge and capacity through the use of advanced techniques and tools (e.g., growth and yield simulators, optimization techniques, tools of communication and graphical representation, among others), that helps to provide support in the decisionmaking process.

This research paper exposes the advantages of using simulation models and optimization models, under a framework of a DSS, for testing alternative management in imbalanced forest structures using as a case study, the management of maritime pine (Pinus pinaster Ait.) forests in Portugal.

Maritime pine is the most represented softwood species in Portugal [12], presenting a high economic, social and ecological interest. Nevertheless, the availability of the resources is below demand levels [13]. The incidence and recurrence of forest fires have strongly impacted the availability of the resources and its future sustainability. According to Centro Pinus [13], pine wood consumption in 2020 was 4.1 million $\mathrm{m}^{3}$ without bark. In 2018, this consumption was over 4.2 million $\mathrm{m}^{3}$, where the availability of this wood was only 2.25 million $\mathrm{m}^{3}$, which supports the fact that wood consumption is higher than its availability and there is a deficit of wood for consumption. In accordance with the possibility of the existing cutting down in the forest, the structural deficit of maritime pine wood amounted to $56.6 \%$ of wood consumption in 2020 . This deficit tends to worsen as Portugal's wildfire risk continues to increase [14], so proper management planning of the forest production function takes on a high importance. Ideal management options considering to climate change expected impacts are not among the ones that can be currently implemented in the common lands as there are two major identified difficulties: presence of large number of naturally regenerated dense areas and lack of policies to favor (costly) adaptive silvicultural measures (e.g., reforestation with improved material; see PEN-CAFoRRCOST Action, http:/ / www.pen-caforr.org/for overall options accessed on 8 March 2021).

It is agreed that the use of DSS helps to efficiently support the management of forest resources. Examples of DSS applied in Portugal are AGFLOR [15] and web-based SADfLOR [16], the former being designed to help assess the impacts of policy changes on regional land use patterns whereas the latter is a complete DSS that integrates an information system, a supply-driven stand level forest simulator and several optimization tools to support forest management planning. In terms of DSS for maritime pine forest, Garcia-Gonzalo et al. [17] applied SADfFLOR to generate strategic management plans for the Leiria National Forest in Portugal aimed at the production of wood. Almost $80 \%$ of the 
state managed area of the Leiria National Forest are even-aged homogeneous stands of maritime pine spanning a large range of ages. Other relevant references are $[18,19]$

The suggested framework of a DSS applied to forest management of maritime pine stands here presented is supported by real data of forest inventory. It concerns a forest area located in the Perimeter Florestal of Barroso, in Ribeira de Pena, in the Northern region of Portugal. This area is made up of common lands, called baldios, which are co-managed by the local communities and the Institute for Nature and Forest Conservation (ICNF). Although these forests provide several products, services, and other benefits, primary incomes are directly related to timber removal following thinning and clear-cutting. With time, the forest disturbances have been altering the forest structure, resulting in a narrow range in terms of stand age. Moreover, the stands that are naturally regenerated after forest fires usually present a reduced or absence of management.

To help with the decision, growth and yield models are available for use in the region [20-23], one of them, the ModisPinaster [22] available as growth simulator of freely use and used in the DSS framework. During the last two decades, efforts have been made to implement the use of these tools, through workshops and dissemination events. Further, optimization models have been developed for more efficient management of these forest resources [24-27].

With this research, the authors want to highlight the importance of DSS and optimization models as a powerful tool to provide decision support in forest management of areas that are structurally unbalanced, showing limited age differentiation, due to fire disturbances and being under pressure from wood utilization. Major differences in forest structure from the case studied by Garcia-Gonzalo et al. (2013) [17], for maritime pine, in Portugal, namely with regard to the range of ages that in [17] is large (nine 10-year age classes are used, between $0-10$ and $>80$ years) and on growth development of the stands, justified the design of a new approach for the forest area considered in the present research.

The DSS framework (Section 2) considers two scenarios with distinct rotation length with the aim of maximizing the volume of timber harvested to meet the interests of the local community. One of the scenarios considers a rotation length of 40 years, in accordance with the traditional silvicultural models. The alternative scenario considers a reduced rotation length of 25 years, approaching the age of harvest of new silvicultural models for the species, suggested in [28]. Managing the stands with shorter rotation lengths can be considered both as an adaptive measure to account for the forest fires risk and a means of providing viable yields from shorter term harvesting.

\section{Materials and Methods}

\subsection{Study Area Characteristics}

The study area is located in North of Portugal, in the Tâmega valley, in the county of Vila Real, Figure 1. It focuses on the communal area of Santo Aleixo, which belongs to the national forest area of Perímetro Florestal do Barroso, occupying 439 ha [29,30].

The available information for each stand was collected on forest inventories and refers to stand area (A, ha); stand age ( $\mathrm{t}$, years); number of trees $(\mathrm{N}$, trees $/ \mathrm{ha})$; stand basal area $(\mathrm{G}$, $\left.\mathrm{m}^{2} \cdot \mathrm{ha}^{-1}\right)$; average diameter $(\mathrm{dg}, \mathrm{cm})$; dominant diameter $\left(\mathrm{d}_{\mathrm{dom}}, \mathrm{m}\right)$ and dominant height $\left(h_{d o m}, m\right)$. The variable $d g$ is calculated as the quadratic mean diameter measured at the height level of $1.30 \mathrm{~m}$ of the living trees. The variable $\mathrm{d}_{\mathrm{dom}}$ corresponds to the average diameter of the largest trees in a basis of the largest 100 trees per hectare. The average height of those dominant trees is the dominant height. A summary of the data is shown in Table 1. 


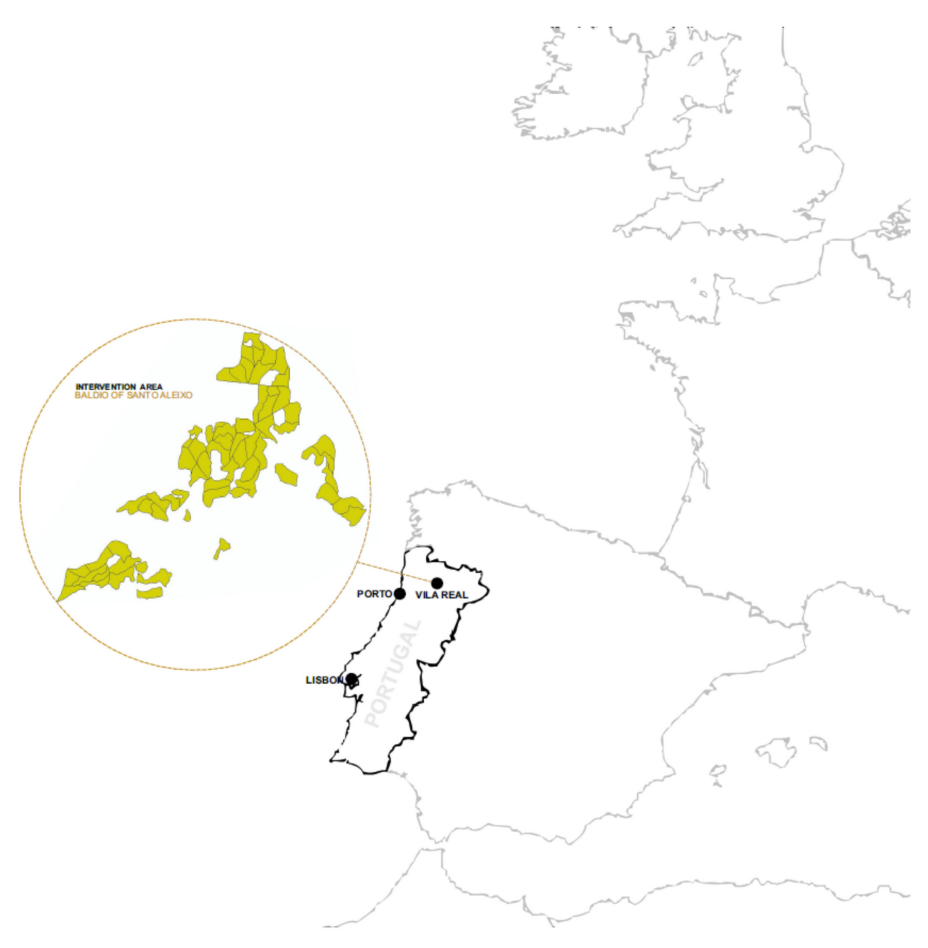

Figure 1. Geographical location of the study area.

Table 1. Summary characteristics of the main variables collected in the studied stands of maritime pine (65 stands/observations).

\begin{tabular}{ccccc}
\hline Variable & Min & Mean & Max & sd \\
\hline $\mathrm{A}(\mathrm{ha})$ & 1.56 & 6.78 & 10.00 & 1.98 \\
$\mathrm{t}(\mathrm{yr})$ & 23 & 32.4 & 47 & 6.3 \\
$\mathrm{~N}\left(\mathrm{trees}^{2} \cdot \mathrm{ha}^{-1}\right)$ & 339 & 706.8 & 1933 & 372 \\
$\mathrm{G}\left(\mathrm{m}^{2} \cdot \mathrm{ha}^{-1}\right)$ & 24.9 & 37.3 & 58.5 & 8.0 \\
$\mathrm{dg}(\mathrm{cm})$ & 17.8 & 27.8 & 39.6 & 6.6 \\
$\mathrm{~d}_{\text {dom }}(\mathrm{cm})$ & 24.2 & 34.1 & 45.8 & 6.5 \\
$\mathrm{~h}_{\text {dom }}(\mathrm{m})$ & 12.2 & 17.5 & 22.5 & 3.0 \\
\hline
\end{tabular}

Legend: A—stand area (ha); t—stand age (yr); N-number of trees per hectare (trees.ha ${ }^{-1}$ ); G-basal area per hectare $\left(\mathrm{m}^{2} \cdot \mathrm{ha}^{-1}\right)$; $\mathrm{dg}$ - quadratic mean diameter measured at the height level of $1.30 \mathrm{~m}(\mathrm{~cm}) ; \mathrm{d}_{\mathrm{dom}}$-dominant diameter $(\mathrm{cm})$; $\mathrm{h}_{\mathrm{dom}}$ —dominant height $(\mathrm{m})$; Min—data minimum; Mean—data average; Max-data maximum; and sd-data standard deviation.

\subsection{Simulation Scenarios Using ModisPinaster}

Growth simulators provide useful information about stand development and production under traditional or user specified silvicultural scenarios, which can be used to support decision making. In this work, the Model with Diameter Distribution for Pinus pinaster (ModisPinaster) was selected as the appropriate simulator as it was developed to be used in the overall region of Tâmega's Valley, where the case study is located. ModisPinaster $[21,22]$ is a model developed for maritime pine, that simulates stand growth and yield, predicts the occurrence of mortality associated with competition or damages from extreme weather events, such as windrow and uprooting, and presents flexibility to select alternative silvicultural procedures to support forest management. It is a model that is available for free use, in a friendly interface, on the Computer Aided Projection of Strategies in Silviculture (CAPSIS) platform (http:/ / www.inra.fr/capsis accessed on 8 March 2021) [31]. A comprehensive explanation of ModisPinaster's components and examples of its use can be seen in a reference by Fonseca et al. [22].

The minimum input data required to the initialization of ModisPinaster is information about the variables stand age $(\mathrm{t}, \mathrm{yr})$; number of trees per hectare $\left(\mathrm{N}\right.$, trees $\left.\cdot \mathrm{ha}^{-1}\right)$; basal area 
per hectare $\left(\mathrm{G}, \mathrm{m}^{2} \cdot \mathrm{ha}^{-1}\right)$; dominant diameter $\left(\mathrm{d}_{\mathrm{dom}}, \mathrm{cm}\right)$ and dominant height $\left(\mathrm{h}_{\mathrm{dom}}, \mathrm{m}\right)$, as defined in Section 2.1.

After initializing ModisPinaster with input data, simulations are run on an anual basis from the initialization point up to a maximum value of 65 years. The model allows testing alternative approaches to density regulation (manual or automatic prescriptions based on spacing factors and density indices, in addition to the usual density measures of number of trees or basal area per hectare) and provides diverse information as output, such as stem volume, biomass (aboveground, per component, and root), carbon, and energy, among other characteristics. The output data is accessible at any age within the simulation period. The authors selected as output information the standing volume and the volume of material that is removed in thinning. These volume values serve as input data in the proposed DSS. We considered a stand density regulation model based on the stand density index (SDI), as defined for maritime pine by Luis and Fonseca (2004) [32], ranging from $35 \%$ (the lower limit of complete occupation) to 55\% (a value close to the lower limit of self-thinning, or natural mortality by competition). That is, when the stand reaches a maximum stipulated value of SDI equal to $55 \%$, the model simulates thinning from below, so that the remaining stand has an SDI equal to $35 \%$.

The simulations were performed for two different scenarios, presented in Figure 2. Scenario 1 consists of maintaining the stand until 25 years of age and, at that age, performing a clear-cut. For stands older than 25 years at the first period, Scenario 1 assumes that a clear-cut is performed in the first year of simulation, and this simulates the growth of a new regenerated stand for another 25 years and a clear-cut is performed again. Scenario 2 consists of letting the stand develop to 40 years of age and then performing a clear-cut at that age. Thinning is only carried out on stands that were managed according to Scenario 2 because, in the case of Scenario 1, as the age of rotation age is 25 years, the inventory data showed that the density of the stands was below the stipulated threshold for thinning.
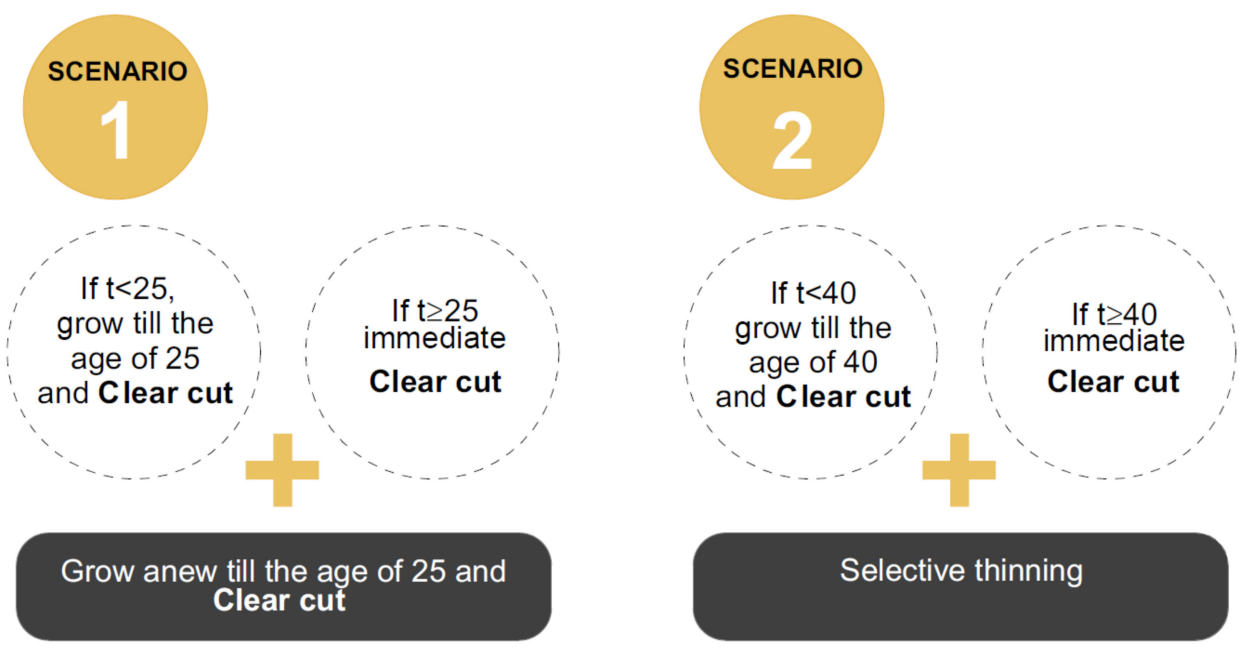

Figure 2. Simulation Scenarios in ModisPinaster.

\subsection{Proposed DSS Structure and Components}

It is intended to create a growth simulator with an interactive interface, which facilitates the user's understanding and is simple to apply and manipulate the results obtained. Through the insertion of the output data obtained with the ModisPinaster model, it is intended that this DSS framework provides management strategies in different time periods and allows the identification of interventions to be performed in the study area. The main objective of this system is to obtain optimal management plans, to optimize the resources provided by this type of forests, considering environmental and sustainability features.

The proposed DSS is composed of an external component, the ModisPinaster model, which performs the initial data processing (simulation of growth over time and of specific 
silvicultural interventions, the thinnings) and of internal components which are the data from ModisPinaster, the optimization model and the user interface. Figure 3 presents the structure and components of the proposed DSS.

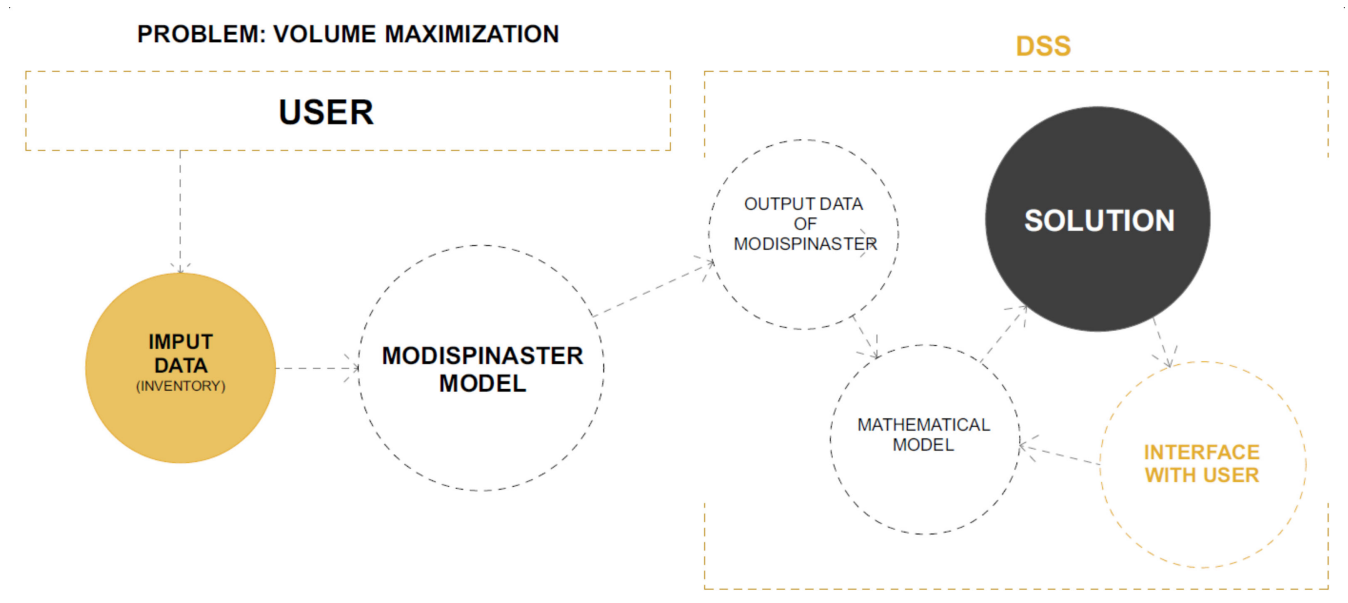

Figure 3. Structure of the DSS framework.

The objective of the DSS model is to maximize the removed timber. Therefore, it is essential to survey management alternatives and to choose the one that best fits the problem, providing the user with a solution corresponding to the maximum achievable volume, while assuring a specified set of constraints.

\subsection{Optimization Model}

This section presents the optimization model to obtain the management plan for a given study area aiming to maximize the harvested timber volume, considering constraints that limit the areas of clearings, and also sustainability, operational and silvicultural constraints. The practices that are considered are thinning and clear-cuts following one of the two scenarios, Scenario 1 and Scenario 2, presented in Section 2.2. The problem consists of determining which set of stands are harvested under Scenario 1 and which are harvested under Scenario 2. In addition, the year/period in which the first clear-cut is performed is also identified.

Let $T=\{1,2, \cdots, n\}$ be the planning horizon with $n$ one-year periods, $P$ be the stands set, and $K$ be the set of age classes.

We assign the following parameters for each stand $j \in P: A_{j}$-area of stand $j(\mathrm{ha}) ; t_{j}$ age (years) of stand $j$ in the first period; $C_{j}^{l}$ and $D_{j}^{l}$-timber volume obtained by, respectively, clearcutting and thinning stand $j$ in period $l\left(\mathrm{~m}^{3}\right) ; S_{j} \subset T$ - set of periods to perform a thinning at stand $j$.

It is also considered parameter $\mathrm{A}_{\max }=10$ ha which is the prescribed value in Portugal for the maximum area that can be cut in the same year and the following two years. To formulate constraints on the maximum clear-cut area and the green-up constraints, consider set $\Re^{l}$ of all possible clusters that cannot be harvested as a whole at period $l$, with $l \in T$, and which are minimal $[27,33]$. Each of these clusters is a contiguous group of stands, whose total area is greater than $A_{\max }$ and that does not contain any similar cluster in the sense that if a stand is excluded from a cluster then the remaining could be cut at once. If $r$ is the number of stands in such a cluster then at most $r-1$ of them can be harvested during the green-up period ( 3 years). It should be noted that two stands are adjacent when both share a boundary that is not a discrete set of points. The minimal infeasible clusters are obtained recursively, starting from clusters with only one stand, and growing them one stand at each time, until the maximum area is met.

We define the following variables: $x_{1}^{l}$ (clearcutting Scenario 1 binary variable) taking value 1 if a clearcutting is performed, adopting Scenario 1 , in stand $j$ in period $l$ and 0 
otherwise; $x_{2 j}^{l}$ (clearcutting Scenario 2 binary variable) taking value 1 if a clearcutting is performed, adopting Scenario 2, in stand $j$ in period $l$ and 0 otherwise; $z_{1 j}$ (Scenario 1 binary variable) taking value 1 if stand $j$ is harvested according Scenario 1 and 0 otherwise; $z_{2 j}$ (Scenario 2 binary variable) taking value 1 if stand $\mathrm{j}$ is harvested according Scenario 2 and 0 otherwise.

In the following is presented the base forest management optimization model, FMO, which aims to maximize the volume of wood harvested during the planning horizon considering only two groups of constraints: the ones that impose that each stand is managed by one of the two scenarios with the suitable ages, constraints (2)-(8), and the ones that limit the area of clearings, constraints (9).

$$
\operatorname{Max} \sum_{j \in P} \sum_{l \in T}\left(C_{j}^{l}+\sum_{l_{1}=1}^{l} D_{j}^{l_{1}}\right)\left(x_{2 j}^{l}+x_{1 j}^{l}\right)
$$

Subject to:

$$
\begin{gathered}
z_{1 j}+z_{2 j}=1 \quad \forall j \in P \\
z_{\mathrm{i} j} \leq \sum_{l \in T} x_{\mathrm{i} j}^{l} \leq 2 z_{\mathrm{i} j} \quad \forall j \in P, \quad i \in\{1,2\} \\
\sum_{l=1}^{t o l+1} x_{1 j}^{l}=z_{1 j} \forall j \in P: 25 \leq t_{j}<40 \\
\sum_{k=l}^{\min (l+t o l, n)} x_{1 j}^{k}=z_{1 j} \forall j \in P, l \in \mathrm{T}: l+t_{j}-1=25, l \geq 2 \\
\sum_{k=l}^{\min (l+t o l, n)} x_{2 j}^{k}=z_{2 j} \forall j \in P, l \in \mathrm{T}: l+t_{j}-1=40, l \geq 2 \\
\sum_{l=1}^{t o l+1}\left(x_{1 j}^{l}+x_{2 j}^{l}\right)=z_{1 j}+z_{2 j} \quad \forall j \in P: t_{j} \geq 40 \\
\sum_{k=l+1}^{\min (l+4, \mathrm{n})}\left(x_{1 j}^{k}+x_{2 j}^{k}\right)=0 \quad \forall j \in P, l \in S_{j} \\
\sum_{i=l}^{l+2} \sum_{j \in R} x_{j}^{l} \leq|R|-1 \quad \forall R \in \Re^{l}, l \in T \\
x_{\mathrm{i} j}^{l}, z_{j}^{l} \in\{0,1\} \quad \forall j \in P, l \in T, i \in\{1,2\}
\end{gathered}
$$

The objective function (1) corresponds to maximization of the volume of timber removed over the planning horizon.

Constraints (2) guarantee that each stand is harvested under one of the two scenarios, 1 or 2. Constraints (3) identify, for each stand, the harvested scenario adopted. Constraints (3) link variables $x$ and $z$, ensuring that if variable $z_{1 j}$ takes the value one then there is at least one clear cut of stand $j$ under Scenario 1, otherwise, no clear-cutting takes place over the planning horizon, under this scenario. Moreover, if variable $z_{2 j}$ takes the value one then there is one clear-cut of stand $j$ under Scenario 2, otherwise, no clear-cutting takes place over the planning horizon under this scenario. Note that a stand can be subjected to a maximum of two clear-cuts whether Scenario 1 or Scenario 2 is adopted.

Constraints (4)-(7) impose conditions on the date of the first clear-cut, considering a tolerance tol years. For a stand with initial age greater or equal to 25 and less than 40 , constraints (4), impose that if Scenario 1 is adopted the first clear-cut must take place in the first period or in the following tol periods. Constraints (5) imposes that if a stand reaches 25 years for an intermediate period and is managed under Scenario 1, then it must be cut in that period or in the following tol periods, as long as it is within the planning horizon. Constraints (6) impose that if a stand reaches 40 years in period $l$ of the planning horizon and is managed according to scenario 2, then it must be cut in that period or the following tol periods. Constraints (7) impose that if the initial age is greater or equal to 40 years then the first clear-cut must take place in the first period or in the following periods within the tolerance tol, independently of being managed according to scenarios 1 or 2 .

Constraints (8) impose an interval of at least four years between interventions, that is, it has to be at least four years between a thinning and a clear-cut. 
Constraints (9) are known as path constraints. These constraints prevent the formation of clear-cuts whose areas are greater than 10 ha and ensure the green-up period requirement $[25,26]$. Constraints (10) establish the variables domain.

Besides constraints (2)-(10), after some computational tests, it was concluded that, although the green-up constraints contribute to ensuring sustainability, they are not sufficient, it would be necessary considering a group of sustainability constraints, which will be described next.

Additional constraints on the final average age and age structure will be included. Let $I_{j}^{l}$ be an integer age variable representing the age, in years, of stand $j$ in period $l$. It holds:

$$
\begin{gathered}
I_{j}^{l}=l+t_{j}-1-\sum_{i=1}^{l}\left(i+t_{j}-1\right)\left(x_{1 j}^{i}+x_{2 j}^{i}\right) \forall j \in P, l \in\{1, \cdots, 25\} \\
I_{j}^{l}=l+t_{j}-1-\sum_{i=1}^{l}\left(i+t_{j}-1\right)\left(x_{1 j}^{i}+x_{2 j}^{i}\right)-25 \sum_{i=1}^{l-25} x_{1 j}^{i}-40 \sum_{i=1}^{n T-40} x_{2 j^{\prime}}^{i} \\
j \in P, l \in\{26, \cdots, n\} \\
I_{j}^{l} \in Z_{0}^{+} \forall j \in P, l \in T
\end{gathered}
$$

The following constraint imposes that the average age of the forest stands at the end of the planning horizon should be at least Ft years:

$$
\sum_{j \in P} I_{j}^{n} A_{j} \geq F t \sum_{j \in P} A_{j}
$$

where $I_{j}^{n}$ is the integer variable corresponding to the age of stand $j$ in the last year of the planning horizon. The obtained model, including this final age constraint, is denoted by FMO_FA.

To ensure sustainability, constraints on the age structure of the forest will be also included. Constraints (15) ensure that, on a period $l$, the area in each age class is within $\left(1-\Delta_{t}\right)$ and $\left(1+\Delta_{t}\right)$ times the target area for each class, Ta:

$$
\left(1-\Delta_{t}\right) T a \leq \sum_{j \in P} w_{j k}^{l} A_{j} \leq\left(1+\Delta_{t}\right) T a, \forall k \in K
$$

where $w_{j k}^{l}$ are age class binary variable taking value 1 if stand $j$ in period $l$ belongs to age class $k$ and 0 otherwise. The obtained model, including the class age constraint, is denoted by FMO_CA.

The following constraints, (16)-(19), should also be included to state the age class that stand $j$ belongs at each period $l$. Considering the age class $k \in K$ be given by $k=\left[L_{k}, U_{k}\right]$, we have:

$$
\begin{gathered}
I_{j}^{l} \leq \sum_{k \in K} U_{k} w_{j k}^{l} \forall j \in P, l \in T \\
I_{j}^{l} \geq \sum_{k \in K} L_{k} w_{j k}^{l} \forall j \in P, l \in T \\
\sum_{k \in K} w_{j k}^{l}=1, \forall j \in P, l \in T \\
w_{j i}^{l} \in\{0,1\} \quad \forall j \in P, l \in T, i \in K
\end{gathered}
$$

As operational constraints, a balanced income over the planning horizon is guaranteed. To do so, the planning horizon is divided into several consecutive periods, $T_{1}, \cdots, T_{d}$, with equal length and it is ensured that the relative difference in the removed volume between two consecutive periods does not exceed $\Delta$ :

$$
(1-\Delta) \text { VolumeP }_{k-1} \leq \text { VolumeP }_{k} \leq(1+\Delta) \text { VolumeP }_{k-1}, k=2, \cdots, d
$$

where Volume $_{k}$ is the volume of timber removed in the $k$-th period, $T_{k}$, given by:

$$
\text { VolumeP } P_{k}=\sum_{j \in P} \sum_{l \in T_{k}}\left(\left(C_{j}^{l}+\sum_{t_{1}=1}^{l} D_{j}^{t_{1}}\right) x_{2 j}^{l}+C_{j}^{l} x_{1 j}^{l}\right), k=1, \cdots, d .
$$


The obtained model, including balanced revenue of volume constraints, is denoted by FMO_RV.

To demonstrate the dynamics of a DSS, the original model was adjusted according to the achieved results. In a first approach, model FMO was considered, where neither the age constraints, nor the revenue regularity were admitted. These sets of constraints were gradually included, resulting in the five models presented in Table 2.

Table 2. Mathematical models' description.

\begin{tabular}{clll}
\hline Model & \multicolumn{1}{c}{ Constraints Characterization } & Equations \\
\hline FMO & - & $\begin{array}{l}\text { Restrictions limiting the area of clearings with } \\
\text { an exclusion period } \\
\text { Restrictions on harvesting according to the age } \\
\text { of the stand and the scenario to be adopted }\end{array}$ & $(1)-(10)$ \\
FMO_FA & - & $\begin{array}{l}\text { FMO's constraints } \\
\text { Bound on the final average age }\end{array}$ & $(1)-(14)$ \\
FMO_CA & - & $\begin{array}{l}\text { FMO's constraints } \\
\text { Area by classes of age regulation }\end{array}$ & $(1)-(13),(15)-(19)$ \\
\hline FMO_RV & - & $\begin{array}{l}\text { FMO's constraints } \\
\text { Balanced revenue of volume }\end{array}$ & $(1)-(10),(20),(21)$, \\
\hline FMO_all & - & $\begin{array}{l}\text { FMO's constraints } \\
\text { Bound on the ending average age } \\
\text { Area by classes of age regulation } \\
\text { Balanced revenue of volume }\end{array}$ & $(1)-(21)$ \\
\hline
\end{tabular}

In order to solve the models, we used the optimization software Xpress 7.2 (available at http:/ / www.fico.com/Xpress accessed on 11 January 2021). Computations were performed on a computer equipped with an i5-2500 3.3 GHZ/3.7 Turbo CPU and 8 GB of RAM. The branch-and-bound algorithm was allowed to run for two hours at the most.

\section{Results}

In this section the computational results for the Santo Aleixo baldio are presented.

\subsection{Remarks about the Model Parameters}

The set P has 65 stands, characterized on Table $1 . n=50$ was considered as the number of years in the planning horizon, and five age classes, $K=\{[0,10],[11,20],[21,30],[31,40]$, $[41,65]\}$ were chosen. The upper bound on the last class is in accordance with the maximum age that the stands can achieve during the planning horizon.

Regarding the tol parameter, constraints (4)-(7), it should be noted that there was a need to make the date of the first clear-cut more flexible due to the clear-cut area constraints because there are several adjacent stands with the same characteristics. After several computational tests, to gets a feasible model, a margin of $t o l=14$ years to perform the first clear-cut is considered, that is, a stand that is in condition to be cut in period $l$ (reached 25 years being harvested according to Scenario 1 or reached 40 years being harvested according to Scenario 2) should be clear-cut in this period or the fourteen following periods. After the first clear-cut, the stand starts a new development phase of natural regeneration and is cut again when it reaches 25 years (for Scenario 1) or 40 years (for Scenario 2).

Furthermore, based on computer experiments, it was considered $F_{t}=20$ for the average age of the stand in the last year, constraints (14).

To get feasible models, due to the age structure of the study area in the beginning of the planning horizon, constraints (15) are only included for the last period, $l=n$, with $\Delta_{t}=0.4$. Moreover, given that the latest cutting age is 40 years, we will consider at the 
end of the planning horizon only the first four area classes in $K$ and, as the total area is 439 hectares, it is considered that $T_{a}=100$ ha.

On constraints (20), ten 5 -year periods, $T_{1}, \ldots, T_{10}$, and $\Delta=0.4$ were considered, values that allow one to find the optimal solution with acceptable variations in the volume of removed timber.

\subsection{Obtained Results with the Framework DSS}

In Figure 4 is presented, as a bar chart, the volume of timber removed per ha, in each five-year period during the planning horizon for formulations FMO and FMO_all.

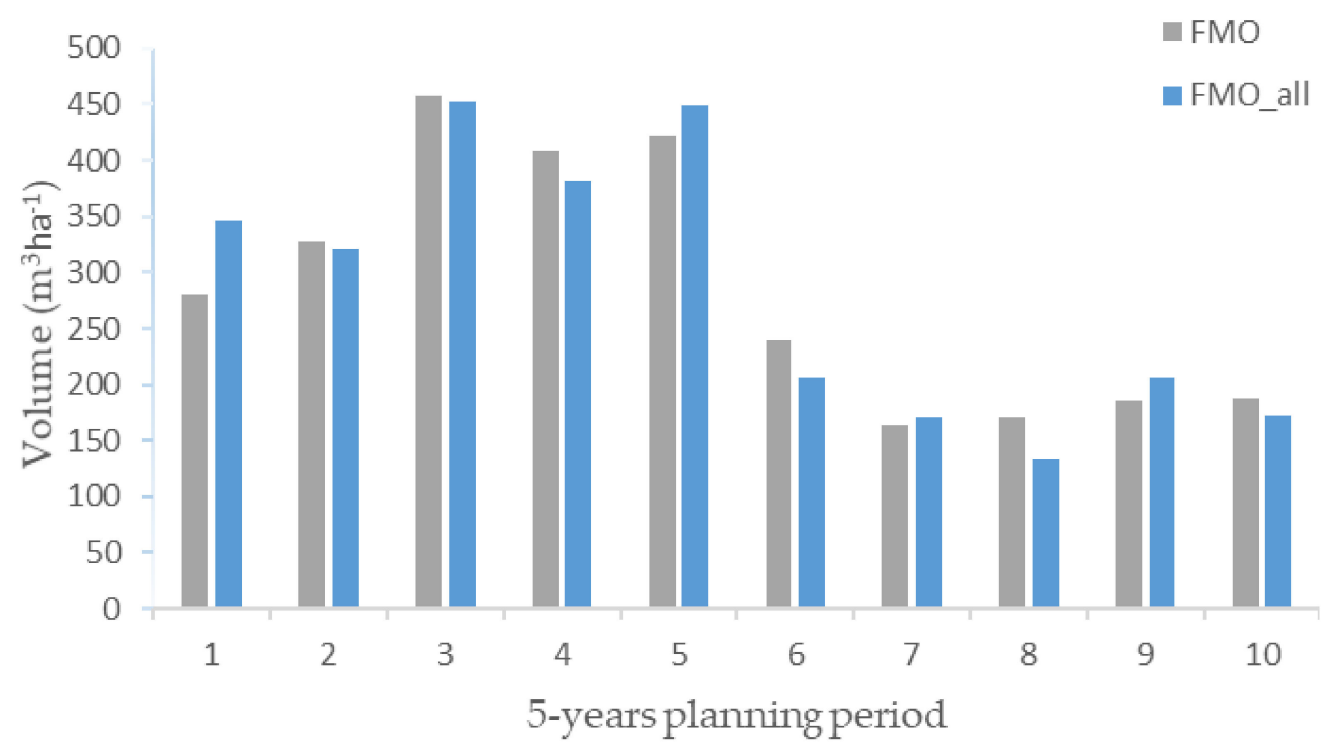

Figure 4. Removed timber volume $\left(\mathrm{m}^{3} \cdot \mathrm{ha}^{-1}\right)$ by each five-years period during the planning horizon with models FMO (base model) and FMO_all (model with all constraints: bounding the final average age, area by classes of age regulation, balanced revenue of volume).

In Table 3, the optimal solutions for the base model, FMO, and the model with all constraints incorporated, FMO_all, are characterized in terms of the number of stands and area managed under each one of the scenarios, as well as the removed timber volume by clearcutting and by thinning, the total removed volume, and the final average age of the maritime pine stands in baldio of Santo Aleixo. The results for the intermediate formulations, FMO_FA, FMO_CA and FMO_RV, are presented on Table A1 in the Appendix A.

Table 3. Characterization of FMO and FMO_all results according to the optimal solution, discriminated by scenario.

\begin{tabular}{ccccc}
\hline \multirow{2}{*}{ Variable } & \multicolumn{2}{c}{ FMO } & \multicolumn{2}{c}{ FMO_all } \\
\cline { 2 - 5 } & Sc1 & Sc2 & Sc1 & Sc2 \\
\hline $\mathrm{n}$ & 47 & 18 & 40 & 25 \\
$\mathrm{~A}(\mathrm{ha})$ & 311.17 & 127.7 & 274.59 & 164.28 \\
vol-cc $\left(\mathrm{m}^{3}\right)$ & $202,194.48$ & $59,854.26$ & $176,507.45$ & $76,647.58$ \\
vol-th $\left(\mathrm{m}^{3}\right)$ & $12,095.06$ & $39,070.38$ & 3362.04 & $44,200.70$ \\
Total vol. $\left(\mathrm{m}^{3}\right)$ & \multicolumn{2}{c}{$313,214.18$} & \multicolumn{2}{c}{$300,717.773$} \\
Final avg. age $(\mathrm{yr})$ & \multicolumn{2}{c}{18.61} & 20.79 \\
\hline
\end{tabular}

Legend: Sc1-Scenario 1; Sc2-Scenario 2; - number of stands; A-area, in ha; vol-cc-volume removed in clear-cut, in $\mathrm{m}^{3}$; vol-th-volume removed by thinning, in $\mathrm{m}^{3}$; Total vol. —-total volume removed; Final avg. age- - the final average age of the stands, in years. 
Tables 4 and 5 characterize by each 5-years of the planning horizon the number of stands and the area managed under scenario 1 and under scenario 2, specifying the practice undertaken, clear cut or thinning, for models FMO and FMO_all, respectively.

Table 4. Characterization of FMO results according to the optimal solution during the planning horizon, discriminated by scenario.

\begin{tabular}{|c|c|c|c|c|c|c|c|c|}
\hline \multirow{3}{*}{$\begin{array}{l}\text { 5-Years } \\
\text { Period }\end{array}$} & \multicolumn{4}{|c|}{ Sc1 } & \multicolumn{4}{|c|}{ Sc2 } \\
\hline & \multicolumn{2}{|c|}{$\mathrm{Cc}$} & \multicolumn{2}{|c|}{ Th } & \multicolumn{2}{|c|}{$\mathrm{Cc}$} & \multicolumn{2}{|c|}{ Th } \\
\hline & $n$ & A (ha) & $n$ & A (ha) & $n$ & A (ha) & $n$ & A (ha) \\
\hline 1 & 4 & 30.45 & 3 & 19.62 & & & 3 & 20.85 \\
\hline 2 & 13 & 88.68 & 6 & 35.46 & & & 13 & 88.98 \\
\hline 3 & 29 & 185.95 & & & & & 2 & 11.83 \\
\hline 4 & 1 & 6.09 & & & 11 & 77.93 & 4 & 28.45 \\
\hline 5 & & & & & 6 & 40.28 & & \\
\hline 6 & 4 & 30.45 & & & 1 & 9.49 & & \\
\hline 7 & 13 & 88.68 & & & & & & \\
\hline 8 & 29 & 185.95 & & & & & & \\
\hline 9 & 1 & 6.09 & & & & & & \\
\hline 10 & & & & & & & 9 & 68.95 \\
\hline
\end{tabular}

Table 5. Characterization of FMO_all results according to the optimal solution during the planning horizon, discriminated by scenario.

\begin{tabular}{|c|c|c|c|c|c|c|c|c|}
\hline \multirow{3}{*}{$\begin{array}{l}\text { 5-Years } \\
\text { Period }\end{array}$} & \multicolumn{4}{|c|}{ Sc1 } & \multicolumn{4}{|c|}{ Sc2 } \\
\hline & \multicolumn{2}{|c|}{$\mathrm{Cc}$} & \multicolumn{2}{|c|}{ Th } & \multicolumn{2}{|c|}{$\mathrm{Cc}$} & \multicolumn{2}{|c|}{ Th } \\
\hline & $n$ & A (ha) & $n$ & A (ha) & $n$ & A (ha) & $n$ & A (ha) \\
\hline 1 & 11 & 77.17 & 2 & 14.89 & & & 5 & 32.75 \\
\hline 2 & 12 & 83.72 & & & & & 16 & 104.28 \\
\hline 3 & 14 & 92.75 & & & 8 & 45.17 & 2 & 11.83 \\
\hline 4 & 3 & 20.95 & & & 8 & 53.63 & 5 & 35.02 \\
\hline 5 & & & & & 8 & 55.99 & & \\
\hline 6 & 11 & 77.17 & & & 1 & 9.49 & & \\
\hline 7 & 12 & 83.72 & & & & & & \\
\hline 8 & 14 & 92.75 & & & & & & \\
\hline 9 & 3 & 20.95 & & & & & 2 & 15.97 \\
\hline 10 & & & & & & & 10 & 60.17 \\
\hline
\end{tabular}

Figure 5 characterizes the area distribution among age classes every 10 years during the planning horizon, from the beginning, decade 0 , to the last year of the planning horizon, decade 5 for the base model FMO, and the model with all constraints incorporated, FMO_all, respectively. Figure A1 in the Appendix A presents the area by class age in the last year of the planning horizon for all the models, FMO, FMO_FA, FMO_CA, FMO_RV, and FMO_all. 


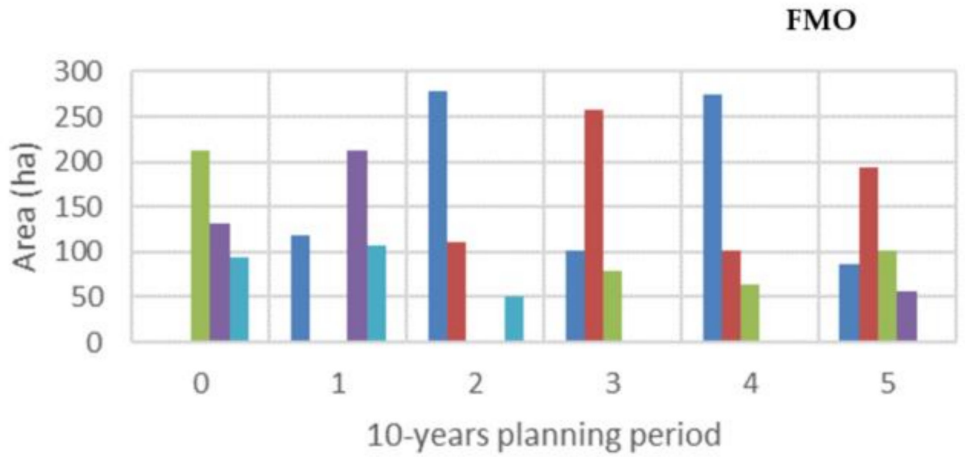

FMO_all

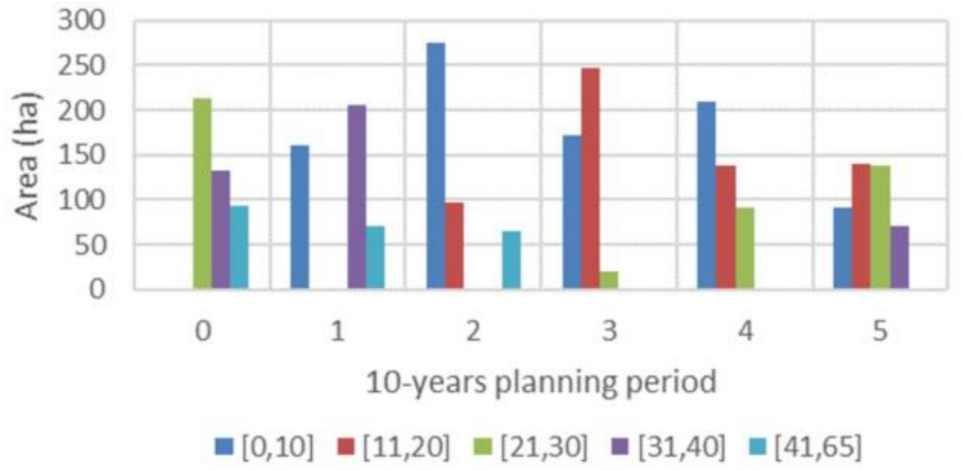

Figure 5. Area by age class during the planning horizon according to the results of model FMO and FMO_all.

Figures 6 and 7 illustrate the spatial representation of the optimal solution obtained with the FMO-all model. The cartography presented concerns about the interventions made during the first ten periods, with the indication of the period in which it takes place. Figure 6 shows the clear cuts and Figure 7 shows the thinning.

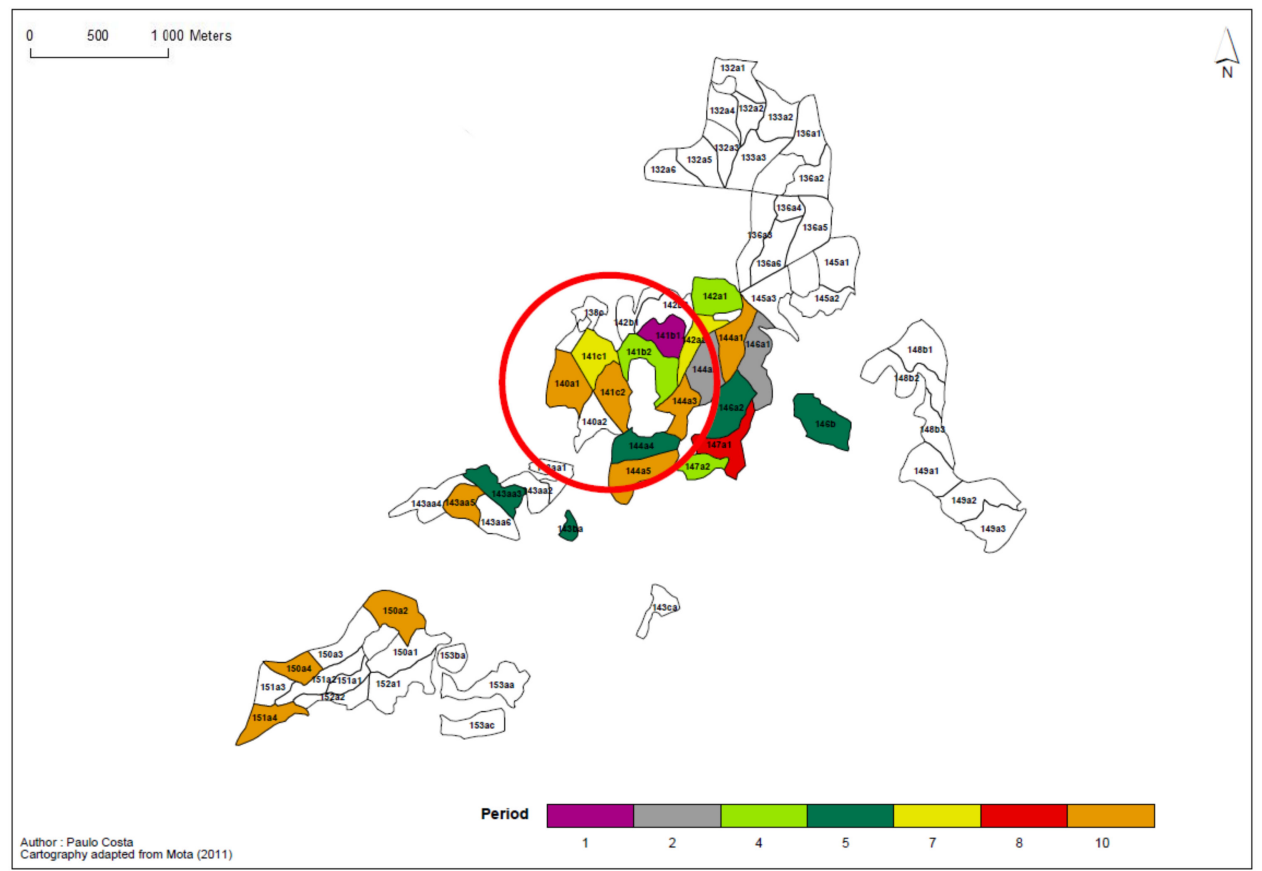

Figure 6. Map of clear cuts to be carried out for periods 1 to 10 of the planning horizon. 


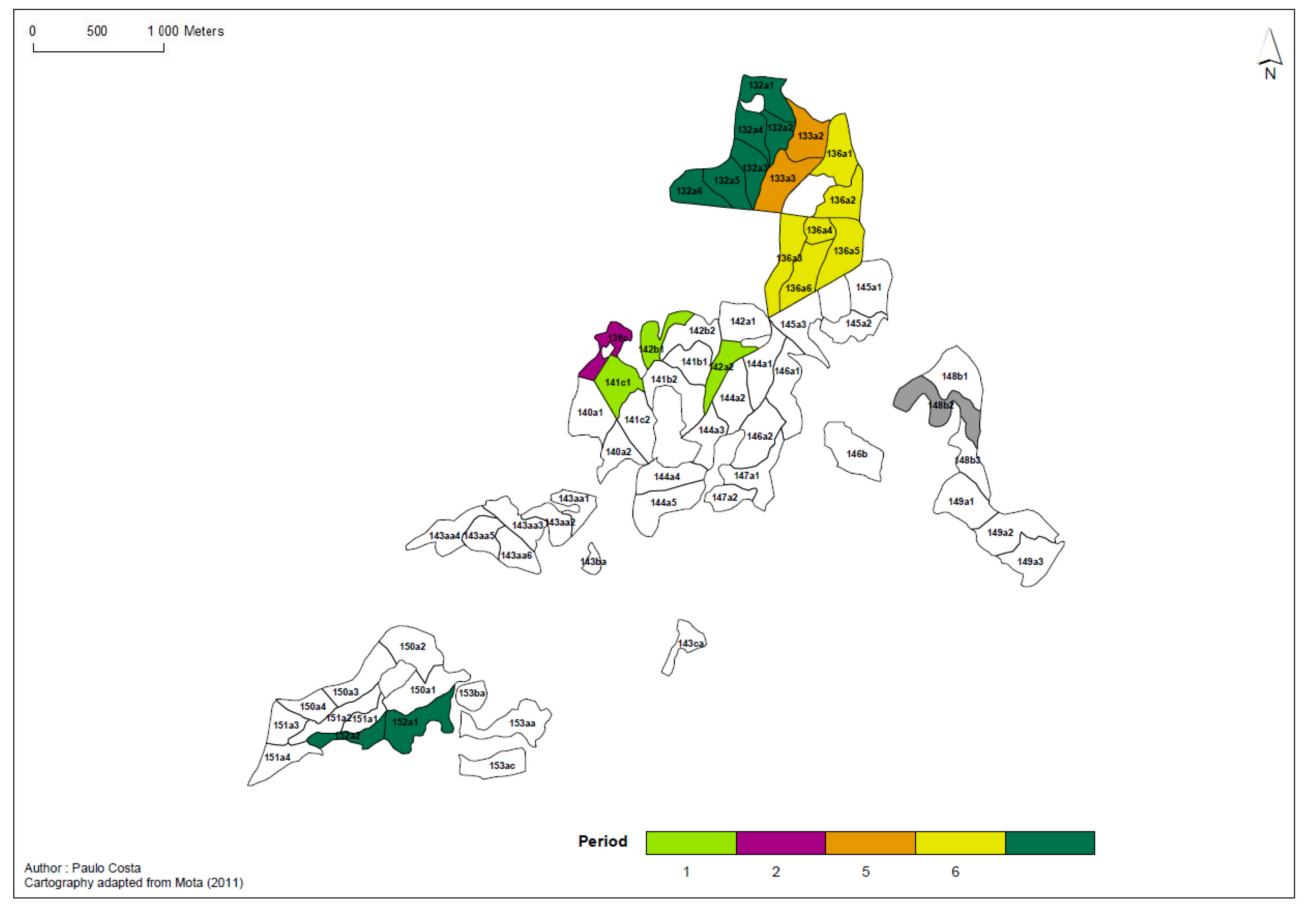

Figure 7. Map of thinning to be carried out for periods 1 to 10 of the planning horizon.

\section{Discussion}

Analysing the results presented in Section 3, in particular Tables 3-5 and Figures 4 and 5 , it can be concluded that although the total volume of harvested timber is smaller with model FMO-all, it is the one that provides a result more coherent with a sustainable management. Similar results have been achieved also in [34], even with the connection with other spatial environmental requirements. In fact, in the optimal solution of model FMO_all the area by age class varies more evenly over the planning horizon, Figure 5, and there are less differences between the removed volume on each 5-year period.

It should be noted that, as the initial age of the stands' study area has a range of values with reduced amplitude it was only possible to obtain feasible problems by imposing constraints (15) only at the end of the planning horizon, which will ensure sustainability in later periods. During the planning horizon, the volume regularity constraints already guarantee revenue over the entire planning period. Regarding the value of the average age of the stand in the last year, $F_{t}$, computational tests were carried out and, in the case of including revenue regularity constraints, (20), the problem becomes infeasible for values of $F_{t}$ greater than 20. With no constraints (20) one can consider $F_{t}=30 \mathrm{but}$, in this case, in the 5-year period from 36 to 40 there is no revenue and in the period from 41 to 45 there is only $743 \mathrm{~m}^{3}$, which does not meet the interests of the populations that are interested in receiving some regular dividend.

Also, if we include in the case $F_{t}=30$ and the constraints (15) we obtain an unfeasible problem. It should be noted that the fact that the area under study has a very unbalanced distribution in terms of areas by age class at the beginning, Table 1 and Figure 5, force the choice of $\Delta$ and $\Delta_{t}$ parameters greater than what could be anticipated, as well as a value of $F_{t}$ lower than expected. However, the model enables to obtain a balanced area class structure in the last year of the planning horizon, which ensures even more balanced planning afterwards. This is the great added value of the work presented.

In the optimal solution of FMO, Table 4, all 47 stands managed under Scenario 1 are subject to two clear cuts during the planning horizon and nine of them undergo thinning in the first decade. The 18 stands managed under Scenario 2 are subject to one clear cut during the planning horizon and all of them are thinned at least once and at most three times. In the optimal solution of FMO_all, Table 5, only two of the stands managed by 
Scenario 1 are thinned, and all 40 stands managed under Scenario 1 are subject to two clear cuts during the planning horizon. The 25 stands managed under Scenario 2 are subject to one clear cut during the planning horizon and only three of them are not thinned while the remaining stands suffer one to three thinnings.

The inclusion of sustainability and operational constraints leads to a reduction in the amount of timber volume harvested by $0.3 \%$ in the case of model FMO_FA, $0.7 \%$ in the case of FMO_CA, 3.8\% in the case of FMO_RV, and 4.0\% in the case of model FMO_all. A reduction on the timber volume was also reported by [17] with the DSS that the authors proposed for maritime pine in Coastal Region of Portugal adding sustainability constraints.

Analysing the solution obtained from FMO_FA and FMO_CA, although the stand age concerns are considered, the revenues are not regular. During the 5-year period from 41 to 45 the amount of extracted volume is greatly reduced, $1133 \mathrm{~m}^{3}$, while in period from 11 to 15 year it is very high, 80,114 and $89,339 \mathrm{~m}^{3}$. This situation is not the most favorable for the local communities who aim to obtain a regular yield over time. Hence the need to include the constraints (20) to prevent large differences in the volume harvested each five-year period, leading to the formulation of model FMO_RV. This model provides wood removals that are more balanced over time.

Analysing Tables 3 and A1, it can be concluded that using any of the models, Scenario 1 is the most adopted, both in number of stands and in the intervened area. This difference is more evident with model FMO, where $70.9 \%$ of the study area is managed under Scenario 1 and the remaining $29.1 \%$ of the area is managed under Scenario 2. For the other models around $65 \%$ of the area is managed under Scenario 1 .

Regarding to the differences between the removed timber volume in thinning and clearcutting, in any of the models, the volume of material removed in clearcutting is much higher, as it would be expected (Tables 3 and A1). In the case of model FMO, the total volume of timber harvested is $313,214.2 \mathrm{~m}^{3}$, of which $83.7 \%$ is from clearcutting and the remaining is originated from thinnings. For the model FMO_all, the total volume of timber harvested is $300,717.8 \mathrm{~m}^{3}$, of which $80.8 \%$ is removed in clear-cut. For the other models, around $83 \%$ of the volume of wood harvested was due to clearcutting.

Figures 6 and 7 show the proposed interventions with FMO-all between periods 1 to 10. There are no interventions in periods 3 and 9. There are two stands, $142 \mathrm{~b} 1$ and 142a2, which are thinned on period 1 and will be clear cut during period 7. In Figure 6 the effect of application of the constraints (9) can be seen, which prevent the creation of clearings with an area larger than 10 ha and guarantees the green-up requirements with an exclusion period of 3 years. A clear-cut is performed at period 1 in stand $141 \mathrm{~b} 1$, and 3 years later an adjacent stand, $141 \mathrm{~b} 2$ is clear cut. Stands $144 \mathrm{a} 2$ and $146 \mathrm{a} 1$ are clear cut on period 2 and only after at least three years will be adjacent stands clear cut: $146 \mathrm{a} 2$ clear cut on period 5; $142 \mathrm{a} 3$ on period $7 ; 144 \mathrm{a} 1$ and $144 \mathrm{a} 3$ on period $10 ; 147 \mathrm{a} 1$ on period 8.

The proposed model is consistent with the management in short rotation and with the specification of the problem that was intended to be studied: it guarantees a balanced age class structure at the end of the planning horizon; it contemplates restrictions on the maximum area of clearings that are in accordance with what is stipulated in Portugal, which is a maximum of 10 hectares; the operational constraints ensure a sustainable management plan that meets the interests of the communities.

Next steps for future development of the proposed model and decision support framework should be incorporating the constraints expressing the different ecosystem services which can change the optimal solution significantly. Even that, the demand for multiple ecosystem services is increasing [35].

In terms of generalization to other cases of study, the proposed approach of a DSS framework can be easily extended or adjusted to application to other regions or forest species, provided that the adequacy of the input information is ensured. This practical implementation encompassed the use of the ModisPinaster model, from which information was acquired for insertion into the proposed optimization model. ModisPinaster was developed for application to maritime pine forests of the northern region of Portugal but 
can be used to support the simulation of pine forests in other regions and countries (Spain, France). As it works to obtain information to support to the DSS, the suitability for other areas (preferably validated before its use) does not limit the interest of the presented DSS. For other species, appropriate forest growth model specific to those species should be selected. The optimization models developed can be used and/or adapted to other regions, regardless of the species, where scenarios that contemplate sustainability constraints such as those indicated in this model are to be studied.

\section{Conclusions}

The research presented refers to forest management planning of stand areas that have grown after rural fire disturbance showing an unbalanced age distribution observed at the beginning of the horizon planning with a narrow range of stand age range.

The selected case study represents not only a real situation but also the expected pattern in the age structure of stands to occur naturally following forest disturbances, such as those associated with recurrent forest fires in Portugal, and generalizable to other causes.

The optimization model created allowed to essay different management alternatives, providing the best one and making a good selection of the available information, in a relatively short period of time. Some difficulties arose during the development of the model because, being in the presence of a common land where the majority of the stands in the study area were more than 25-30 years old, the implementation of interventions became quite restrictive in the sense that if no rules were imposed on the implementation of interventions, the planning horizon would end with a very low average age. As output information, the users have a table indicating what to do in each stand and throughout the planning horizon (we chose not to include it in this article so as not to make it too long), and maps that provide a spatial and temporal perception of the common land area and the interventions to be performed.

The application performed makes the forest management process more efficient, ensuring the satisfaction of legal requirements, the sustainability of resources and the balance of revenues. Further developments should enlarge the optimization problem in order to take into account the broad role and multiple functions of forests. For pine forests, two of the relevant functions that might be of importance for the DSS are the production of resin and the carbon sequestration.

Author Contributions: Conceptualization, P.C., A.C. and T.F.F.; methodology, all the authors; software, P.C., A.C. and T.F.F.; formal analysis, all the authors; investigation, P.C., A.C. and T.F.F.; resources, A.C. and T.F.F.; writing-original draft preparation, P.C., A.C. and T.F.F.; writing-review and editing, P.C., A.C. and T.F.F.; supervision, A.C., J.K., R.M. and T.F.F. All authors have read and agreed to the published version of the manuscript.

Funding: The participation of the corresponding author Paulo Costa was partially funded by Erasmus+ Program in a mission to Faculty of Forestry and Wood Sciences, Czech University of Life Sciences Prague, Czech Republic, under grant 29231-LA-1-2014-1-PT-E4AKA1-ECHE. The participation of the co-author Teresa Fonseca was financed by the Forest Research Centre, a research unit funded by Fundação para a Ciência e a Tecnologia I.P. (FCT), Portugal (UID/00239/2020). The participation of the co-author Adelaide Cerveira was financed by National Funds through the Portuguese funding agency, FCT-Fundação para a Ciência e Tecnologia, within project: UIDB/50014/2020. Jan Kašpar and Róbert Marušák have been supported by the EVA4 project "Ad-vanced Research Supporting the Forestry and Wood-processing Sector's Adaptation to GlobalChange and the 4th Industrial Revolution" (CZ.02.1.01/0.0/0.0/16_019/0000803) in the Czech University of LifeSciences, Prague.

Institutional Review Board Statement: Not applicable.

Informed Consent Statement: Not applicable.

Data Availability Statement: The data are not public available.

Acknowledgments: The authors acnowledge Artur Mota for providing inventory data.

Conflicts of Interest: The authors declare no conflict of interest. 


\section{Appendix A. Complementary Results}

This section presents results for the intermediate models, FMO_FA (model with constraints bounding the final average age), FMO_CA (model with area by classes of age regulation constraints), and FMO_RV (model with balanced revenue of volume constraints).

In Table A1, the optimal solutions for models FMO_FA, FMO_CA and FMO_RV are characterized in terms of the number of stands and area managed under each one of the scenarios, as well as the removed timber volume by clearcutting and by thinning, the total removed volume, and the final average.

Table A1. Characterization of FMO_CA, FMO_CA, and FMO_CA results according to the optimal solution, discriminated by scenario.

\begin{tabular}{ccccccc}
\hline \multirow{2}{*}{ Variable } & \multicolumn{2}{c}{ FMO_FA } & \multicolumn{2}{c}{ FMO_CA } & \multicolumn{2}{c}{ FMO_RV } \\
\cline { 2 - 6 } & Sc1 & Sc2 & Sc1 & Sc2 & Sc1 & Sc2 \\
\hline$n$ & 43 & 22 & 43 & 22 & 41 & 24 \\
A (ha) & 283.73 & 155.14 & 287.07 & 151.8 & 275.81 & 163.06 \\
vol-cc $\left(\mathrm{m}^{3}\right)$ & $188,177.09$ & $73,626.32$ & $189,221.62$ & $70,794.05$ & $177,254.97$ & $76,453.52$ \\
vol-th $\left(\mathrm{m}^{3}\right)$ & $12,870.07$ & $37,547.97$ & $10,555.79$ & $40,358.23$ & 4002.40 & $43,508.24$ \\
Total vol. $\left(\mathrm{m}^{3}\right)$ & \multicolumn{2}{c}{$312,221.455$} & \multicolumn{2}{c}{$310,929.692$} & $301,219.129$ \\
Final avg. age $(\mathrm{yr})$ & \multicolumn{2}{c}{20.00} & \multicolumn{2}{c}{19.65} & 20.68 \\
\hline
\end{tabular}

Legend: Sc1-Scenario 1; Sc2—Scenario 2; n—number of stands; A—area, in ha; vol-cc—volume removed in clear-cut, in $\mathrm{m}^{3}$; vol-th—volume removed by thinning, in $\mathrm{m}^{3}$; Total vol.—-total volume removed; Final avg. age- - the final average age of the stands, in years.

Figure A1 presents the area by class age in the last year of the planning horizon in the optimal solution for all the models, FMO, FMO_FA, FMO_CA, FMO_RV, and FMO_all.

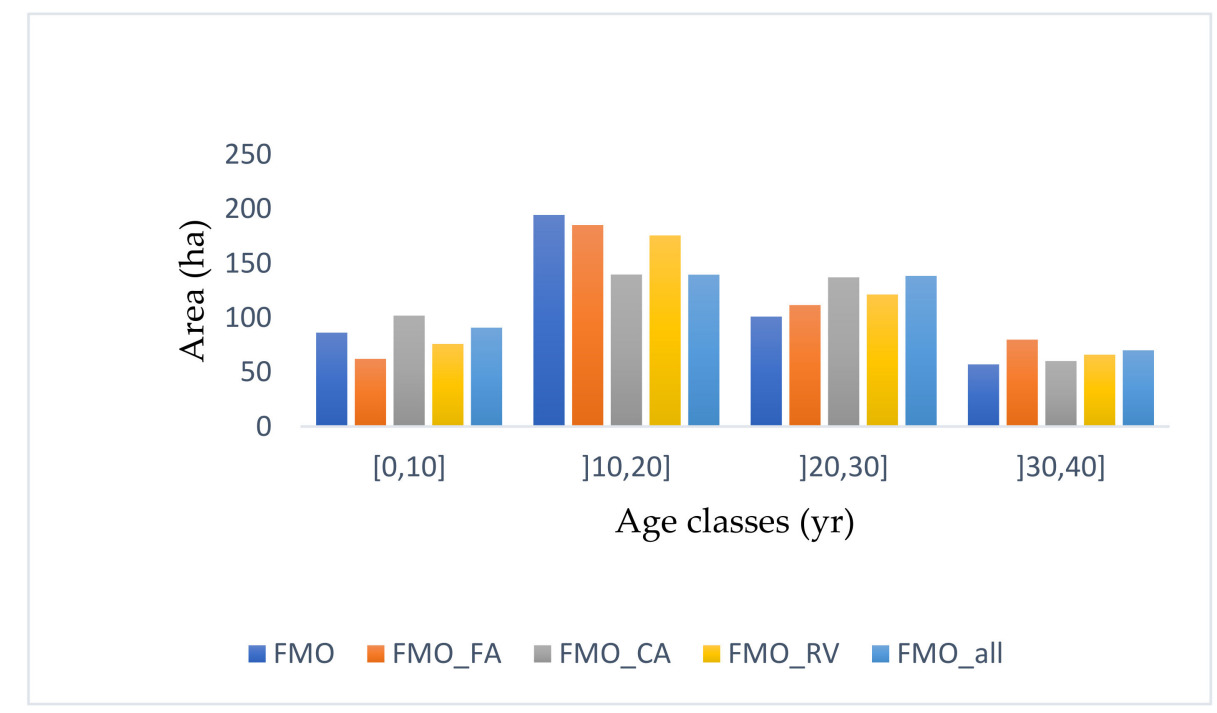

Figure A1. Area by age class in the last year of the planning horizon according to the results of all models.

\section{References}

1. Clutter, J.L.; Fortson, J.C.; Pienaar, L.V.; Brister, G.H.; Baily, R.L. Timber Management: A Quantitative Approach; John Wiley and Sons: New York, NY, USA, 1983; p. 333.

2. Keen, P. Decision Support Systems: A Research Perspective; Addison-Wesley: Boston, MA, USA, 1978; p. 264.

3. Sprague, R.H., Jr. A Framework for the Development of Decision Support Systems. MIS Q. 1980, 4, 1-25. [CrossRef]

4. Igbaria, M.; Sprague, R.H., Jr.; Basnet, C.; Foulds, L. The impact and benefits of a DSS: The case of FleetManager. Inf. Manag. 1996, 31, 215-225. [CrossRef]

5. Shim, J.P.; Warkentin, M.; Courtney, J.F.; Power, D.J.; Sharda, R.; Christer, C. Past, present, and future of decision support technology. Decis. Support Syst. 2002, 33, 111-126. [CrossRef] 
6. Hung, S.-Y.; Ku, Y.-C.; Liang, T.-P.; Lee, C.-J. Regret avoidance as a measure of DSS success: An exploratory study. Decis. Support Syst. 2007, 42, 2093-2106. [CrossRef]

7. Pick, R.A. Benefits of Decision Support Systems. In Handbook on Decision Support Systems 1; Springer: Berlin/Heidelberg, Germany, 2008; pp. 719-730.

8. Power, D.J.; Sharda, R. Decision Support Systems. In Springer Handbook of Automation-Part I; Nof, S., Ed.; Springer: Berlin/Heidelberg, Germany, 2009; pp. 1539-1548.

9. Keen, P.G.W. Value Analysis: Justifying Decision Support Systems. MIS Q. 1981, 5, 1-15. [CrossRef]

10. Reynolds, K.M.; Twery, M.; Lexer, M.J.; Vacik, H.; Ray, D.; Shao, G.; Borges, J.G. Decision support systems in natural resource management. In Handbook on Decision Support Systems; Burstein, F., Holsapple, C., Eds.; Springer: Berlin, Germany, 2008; Volume 2, pp. 499-534.

11. Segura, M.; Ray, D.; Maroto, C. Decision support systems for forest management: A comparative analysis and assessment. Comput. Electron. Agric. 2014, 101, 55-67. [CrossRef]

12. 6. ${ }^{\circ}$ Inventário Florestal Nacional 2015-Relatório Final. Instituto da Conservação da Natureza e das Florestal. Available online: http:/ / www2.icnf.pt/portal/ florestas/ifn/resource/doc/ifn/ifn6/IFN6_Relatorio_completo-2019-11-28.pdf (accessed on 28 March 2021).

13. Centro Pinus. A Fileira do Pinho em 2018-Indicadores da Fileira do Pinho. 2019. Available online: https://www.centropinus. org/files/upload/indicadores/indicadores-centro-pinus-2019-vf.pdf (accessed on 19 July 2021).

14. Beighley, M.; Hyde, A.C.; Portugal Wildfire Management in a New Era Assessing Fire Risks. Resources and Reforms February. 2018. Available online: https://www.isa.ulisboa.pt/files/cef/pub/articles/2018-04/2018_Portugal_Wildfire_Management_in_a_ New_Era_Engish.pdf (accessed on 27 July 2021).

15. Borges, P.J.; Fragoso, R.; Garcia-Gonzalo, J.; Borges, J.G.; Marques Lucas, S. Assessing impacts of Common Agricultural Policy changes on regional land use patterns with a decision support system: An application in Southern Portugal. For. Policy Econ. 2010, 12, 111-120. [CrossRef]

16. Marto, M.; Reynolds, K.M.; Borges, J.G.; Bushenkov, V.A.; Marques, S.; Marques, M.; Barreiro, S.; Botequim, B.; Tomé, M. Web-Based Forest Resources Management Decision Support System. Forests 2019, 10, 1079. [CrossRef]

17. Garcia-Gonzalo, J.; Palma, J.H.N.; Freire, J.P.A.; Tome, M.; Mateus, R.; Rodriguez, L.C.E.; Bushenkov, V.; Borges, J.G. A decision support system for a multi stakeholder's decision process in a Portuguese National Forest. For. Syst. 2013, 22, 359. [CrossRef]

18. Garcia-Gonzalo, J.; Borges, J.G.; Palma, J.H.N.; Zubizarreta-Gerendiain, A. A decision support system for management plan-ning of Eucalyptus plantations facing climate change. Ann. For. Sci. 2014, 71, 187-199. [CrossRef]

19. Falcão, A.; Borges, J.G. Designing decision support tools for Mediterranean forest ecosystems management: A case study in Portugal. Ann. For. Sci. 2005, 62, 751-760. [CrossRef]

20. Moreira, A.M.; Fonseca, T.F. Tabela de produção para o pinhal do Vale do Tâmega. Silva Lusitana 2002, 10 , 63-71.

21. Fonseca, T.F. Modeling the Growth, Mortality and Diametric Distribution of Maritime Pine Forest in the Tâmega Valley (Modelação do Crescimento, Mortalidade e Distribuição Diamétrica, do Pinhal Bravo no Vale do Tâmega). Ph.D. Thesis, Universidade de Trás-os-Montes e Alto Douro, Vila Real, Portugal, 2004.

22. Fonseca, T.F.; Parresol, B.; Marques, C.; de Coligny, F. Models to Implement a Sustainable Forest Management-An Overview of the ModisPinaster Model. In Sustainable Forest Management/Book 1; Martín, J.G., Diez Casero, J.J., Eds.; InTech-Open Access Publisher: London, UK, 2012; pp. 321-338.

23. Fonseca, T.F.; Carneiro, S. Ferramentas de Apoio à Gestão de Pinhal-Bravo: Tabelas de Produção; Centro PINUS: Rio de Mouro, Portugal, 2019 ; p. 40.

24. Cerveira, A.; Fonseca, T.; Mota, A.; Martins, I. An Integer Programming Model for the Management of a Forest in the North of Portugal. In Numerical Analysis Applied Mathematics ICNAAM 2011: International Conference on Numerical Analysis and Applied Mathematics; Simos, T.E., Psihoyios, G., Tsitouras, C., Anastassi, Z., Eds.; AIP: Melville, NY, USA, 2011; pp. $1890-1893$.

25. Fonseca, T.F.; Cerveira, A.; Mota, A. An integer programming model for a forest harvest problem with temporal and con-straints. For. Syst. 2012, 21, 272-283.

26. Martins, I.; Cerveira, A.; Mota, A.; Bento, J.; Fonseca, T. Sustainable Management of a Northern Portugal Forest, Recent Researches in Environment, Energy Systems and Sustainability. In Proceedings of the 8th WSEAS International Conference on EEESD'12; Ramos, R.A.R., Straupe, I., Panagopoulos, T., Eds.; WSEAS Press: Algarve, Portugal, 2012; pp. 232-237.

27. Cerveira, A.; Martins, I.; Mota, A.; Bento, J.; Fonseca, T.F. Otimização de Planos de Exploração Florestal em Baldios do Norte de Portugal. In Investigação Operacional em Ação—Casos de Aplicação; Oliveira, R.C., Ferreira, J.S., Eds.; Imprensa da Universidade de Coimbra: Coimbra, Portugal, 2014; pp. 17-56.

28. Fonseca, T.F.; Lousada, J.L. Management of Maritime Pine: Energetic Potential with Alternative Silvicultural Guidelines. In Forest Biomass_From Trees to Energy; Gonçalves, C., Sousa, A., Malico, I., Eds.; InTech-Open Access Publisher: London, UK, 2021; pp. 71-86.

29. Mota, A.A.R. Exploitation Plan for Pinus Pinaster Ait. In the Ribeira de Pena Forest Reserve, Barroso Forested Area (Plano de Exploração para Pinus Pinaster Ait. dos Baldios de Ribeira de Pena, Perimetro Florestal do Barroso). Master's Thesis, Universidade de Trás-os-Montes e Alto Douro, Vila Real, Portugal, 2011. 
30. Costa, P. Decision Support Systems Applied to Sustainable Forest Management in Pinus Pinaster Ait. (Sistemas de Suporte à Decisão Aplicados à Gestão Florestal Sustentável em Povoamentos de Pinus Pinaster Ait.). Master's Thesis, Universidade de Trás-os-Montes e Alto Douro, Vila Real, Portugal, 2017.

31. Dufour-Kowalski, S.; Courbaud, B.; Dreyfus, P.; Meredieu, C.; de Coligny, F. Capsis: An open software framework and com-munity for forest growth modelling. Ann. For. Sci. 2012, 69, 221-233. [CrossRef]

32. Luis, J.S.; Fonseca, T.F. The allometric model in the stand density management of Pinus pinaster in Portugal. Ann. For. Sci. 2004, 61, 807-814. [CrossRef]

33. McDill, M.E.; Rebain, S.A.; Braze, J. Harvest scheduling with area-based adjacency constraints. For. Sci. 2002, 48, 631-642.

34. Marušák, R.; Kašpar, J. Spatially-constrained harvest scheduling with respect to environmental requirements and silvicultural. For. J. 2015, 61, 71-77.

35. Baskent, E.Z.; Borges, J.G.; Kašpar, J.; Tahri, M. A Design for Addressing Multiple Ecosystem Services in Forest Management Planning. Forests 2020, 11, 1108. [CrossRef] 